\title{
Rare cause of seizures: ruptured intracranial dermoid cyst
}

elSSN: 2383-4625

Received: 21 February 2018

Revised: 1 April 2018

Accepted: 6 April 2018

Correspondence to: Rohat Ak Emergency Department, Şehit Prof. Dr. IIlhan Varank Sancaktepe Education and Research Hospital, Emek Mahallesi, Namık Kemal Cd., 34785 Dudullu Osb/ Sancaktepe, Istanbul, Turkey E-mail: rohatakmd@gmail.com ORCID

http://orcid.org/0000-0002-8324-3264

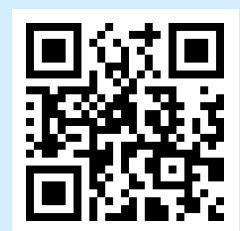

How to cite this article:

Ak R, Doğanay F, Doğan M. Rare cause of seizures: ruptured intracranial dermoid cyst. Clin Exp Emerg Med 2019 Feb 12. Clin Exp Emerg Med 2019;6(1):89-90.

What is new in the current study

Dermoid cysts should be considered in the differential diagnosis of seizures and total removal is recommended when possible.
This is an Open Access article distributed under the terms of the Creative Commons Attribution Non-Commercial License (http:// creativecommons.org/licenses/by-nc/4.0/). 


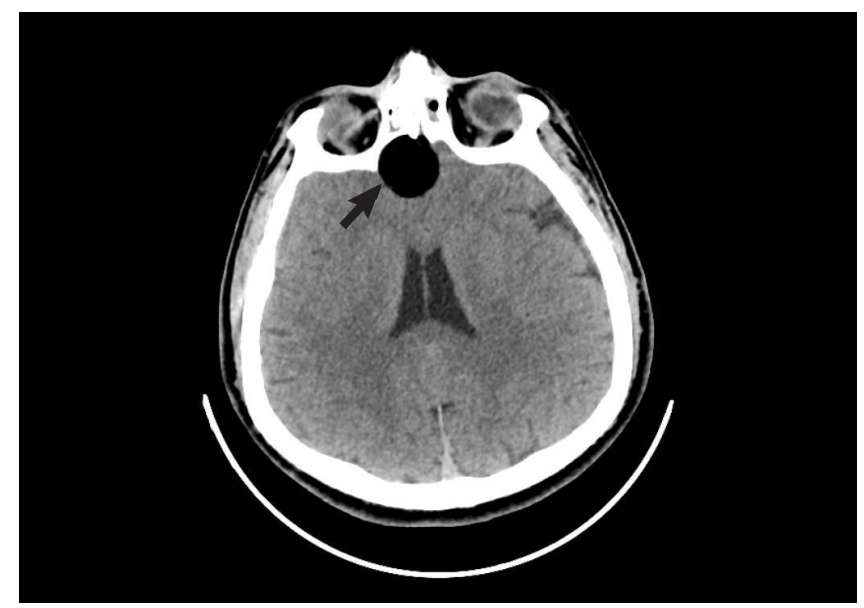

Fig. 1. Axial computed tomography images demonstrate a $16 \times 22-\mathrm{mm}$ diameter solid fat density lesion in the frontal lobe (arrow).

\section{CONFLICT OF INTEREST}

No potential conflict of interest relevant to this article was reported.

\section{REFERENCES}

1. Ray MJ, Barnett DW, Snipes GJ, Layton KF, Opatowsky MJ. Ruptured intracranial dermoid cyst. Proc (Bayl Univ Med Cent)

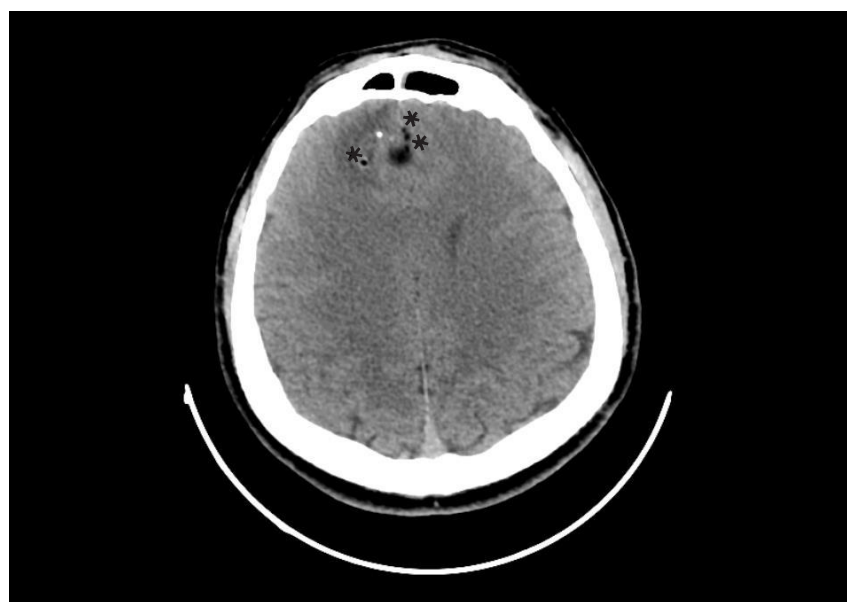

Fig. 2. Axial computed tomography images demonstrate multiple locules of fat, suggesting cyst rupture (asterisks).

2012;25:23-5.

2. Das CJ, Tahir M, Debnath J, Pangtey GS. Neurological picture: ruptured intracranial dermoid. J Neurol Neurosurg Psychiatry 2007;78:624-5.

3. Heger $D$, Scheer $F$, Andresen R. Ruptured, intracranial dermoid cyst: a visual diagnosis? J Clin Diagn Res 2016;10:TD08-9.

4. Wani AA, Raswan US, Malik NK, Ramzan AU. Posterior fossa ruptured dermoid cyst presenting with hydrocephalus. Neurosciences (Riyadh) 2016;21:358-60. 